\title{
Notes on Transliteration
}

\author{
THE THAI LANGUAGE
}

Spoken Thai is a member of the Sino-Tibetan group of languages. The ancestors of most of the people who now live in Thailand migrated from southern China during the seventh and eighth centuries B.E. (Buddhist era), along with other Tai peoples, including the Lao (whose language remains very similar to Thai). Written Thai was developed during the thirteenth century, C.E., and is one of many offshoots of the Devanagari writing system, which originated in India. The modern Thai alphabet contains forty consonants and twenty-four vowels, and the spoken language uses five tones (middle, high, low, rising, and falling). ${ }^{1}$ This means that two or more words may be spelled the same but have entirely different meanings because they are pronounced with different tones. For example, the word maa means "to come" when it is pronounced with a level tone, but it means "horse" when pronounced with a high tone, máa; and it means "dog" when pronounced with a rising tone, măa. The non-Thai-speaking reader may be pleased to learn that these interesting facts are of no consequence at all in terms of reading and understanding the selections in this anthology.

\section{TRANSLITERATION}

The representation of Thai words in English presents several problems. First, no system of transliteration is fully adequate to convey actual pronunciation. Second, the systems of transliteration used by linguists are seldom comprehensible to the general reader of fiction, for example, the representation of the vowel sound " $a$ " as in hat using the symbol $\varepsilon$, or the vowel sound "aw" as in lawn using the symbol 0 . I have tried to achieve an acceptable compromise by using in the selections an accessible transliteration of Thai words for the nonlinguistically oriented, and in the introduction, footnotes, and biograph-

1. This describes the central Thai dialect, which is taught in schools throughout the nation; there are regional tonal variations. 
ical sketches-where its use seems warranted-a transliteration based upon the system developed by Mary Haas and refined by J. Marvin Brown, for example, "the poetic epic Khun Chang Khun Phaen, or Khun Cháang Khun Phecn." Where the latter, phonetic system of transliteration is used, pronunciation follows these rules:

Transliterated

Thai Vowel

Approximate Pronunciation

a / aa

ah / aaaah

i / ii

hit / heat

$\mathrm{u} / \mathrm{uu}$

put / pool

$\mathfrak{u} / \mathrm{u}$

no corresponding vowel in English; it is similar to

German $\ddot{u}$ and has a short and long version, like the other simple Thai vowels

e / ee

hay / longer version of same vowel sound

ว / әә

her / longer version of same vowel sound

$\varepsilon / \varepsilon \varepsilon$

hat / longer version of same vowel sound

o / oo

rope / longer version of same vowel sound

ว / כo

lawn / longer version of same vowel sound

Dipthongs

ua

ia

truant

idea

ta

combines $z$ (see above) with $a$

Transliterated

Thai Consonant

b

$b$ as in bat

p

$p b$ as in top boy

ph

$p$ as in pen

k

hard $g$ as in $g o$

$\mathrm{kh}$

$k$ as in keep

d

$d$ as in door

$\mathrm{t}$

$t d$ as in hot dog

th

$t$ as in top

ng

$n g$ as in sing ( $n g$ is also used as an initial consonant, as in the word $n g u u$, "snake")

Consonants that do not appear above ( $m, n, s$, and so on) may be assumed to have the same pronunciation in Thai that they have in English. 
Thai script is included in the bibliography for the convenience of those who read Thai and will find it helpful in tracking down a particular book or article. The English spellings of authors' names reflect their own preference if it is known; otherwise, I have used the spelling that seems most reasonable to me. 
